"'Find Out Exactly What to Think - Next!': Chris Morris, Brass Eye and Journalistic Authority"

\title{
Graham Meikle
}

\begin{abstract}
This article discusses Chris Morris's fake news TV series Brass Eye (1997, 2001). It concentrates on the ways in which Brass Eye exposed and undermined not only the textual conventions of TV news and current affairs, but also the ways in which the program deployed those textual conventions to highlight and sabotage the cultural authority of public figures who appeared on it. The article first introduces Morris and Brass Eye, before identifying some of the key textual strategies of broadcast news that are satirized in the program, including its mode of address, its music, and its visuals and graphics. It then examines how the program's use of those strategies enables it to exercise the authority of broadcast news to expose the accessed voices of public figures within the show.
\end{abstract}




\section{Introduction - News and Fake News}

News is the organized daily production, distribution and uses of non-fiction drama. News is an industrial product — shaped and marketed by news organizations — but also a cultural product, drawing upon and contributing to our understandings of narrative and drama, of shared time and space, of our senses of ourselves and our communities. And news is also a representation of social and cultural authority, in which authorized storytellers present the pronouncements and activities of other authorities. News is a textual system which encapsulates who gets to speak and what they get to speak about: "news represents who are the authorized knowers and what are their authoritative versions of reality" (Ericson, Baranek \& Chan, 1989, p. 3, emphasis in original).

Such a system of textual authority, built around claims to define reality by defining what counts as true and important, is a clear target for satire - understood here as art on the attack - to include both its aesthetic and its critical dimensions. Satirical fake news is where these authorized knowers and their authoritative versions of reality are called into question. Fake news is where fictional and non-fictional drama combine, blur or merge; where nonfictional events and people — actual news footage, actual public figures — are brought within a fictional frame, highlighting the constructed aspects of the "real" (Day, 2009). Fake news is an important part of a television landscape in transition, as producers and viewers respond to the possibilities of increased choice and control (Lotz, 2007); to new technological possibilities for production, distribution, and reception (Meikle \& Redden, 2011); and to shifting contexts of popular culture, in which contending claims on authority, identity, and attention compete with those of formerly accredited experts (Jones, 2010). Fake news is an important part of a complex televisual environment in which questions of real and fake are in ongoing tension, and in which all forms of factual programming depend on increasing degrees of artifice in the pursuit of the real (Roscoe \& Hight, 2001; Kilborn, 2003).

The concept of satirical fake news has attracted growing attention in recent years (Boler \& Turpin, 2008; Gray, Jones \& Thompson, 2009; Baym, 2010; Jones, 2010), even meriting an entry in a major published glossary of keywords in news and journalism for students (Zelizer \& Allan, 2010, p. 41). Gray, Jones, and Thompson (2009) offer a range of 
reasons for the importance of such satirical TV - its sheer popularity, its viral circulation and implication with the emergence of new technological apparatus for television, its complex relationships with conceptions of humor, its practitioners' willingness to take on a Fourth Estate role that real journalists all too often relinquish, and its capacity to energize public discussion (p. 4). A central claim of much discussion of fake news is that in highlighting the artifices and textual strategies of TV news and political programming, the "fake" highlights the workings of the "real," drawing attention to the ways in which reality is constructed and represented (Druick, 2009, for example).

This article discusses a landmark fake news TV series from the UK, Chris Morris's Brass Eye (1997, 2001). It concentrates on the ways in which Brass Eye exposed and undermined not only the textual conventions of TV news and current affairs, but also the ways in which the program deployed those textual conventions to highlight and sabotage the cultural authority of public figures who appeared on it. Brass Eye was important because it showed its viewers the limits and the often worthless foundations on which such claims to authority are built. This article first introduces Morris and Brass Eye, before identifying some of the key textual strategies of broadcast news that are satirized in the program, including its mode of address, its music, and its visuals and graphics. It then examines how the program's use of those strategies enables it to exercise the authority of broadcast news to undermine the voices of public figures within the show, enabling Brass Eye to point to larger questions of social and cultural authority.

\section{Chris Morris and Brass Eye}

Chris Morris (born 1962) has worked across a broad spectrum of media since beginning his career in the late 1980s on BBC radio. He has broadcast on both local and national BBC radio stations, including the flagship national youth-oriented network Radio 1. His TV work includes the Jam version of his disturbing Blue Jam radio series, and co-writing the 2005 Channel 4 sitcom Nathan Barley — about a London hipster and "self-facilitating media node" - with columnist and TV presenter Charlie Brooker; Morris has also acted in the sitcom The IT Crowd. In 1999, Morris wrote a series of spoof newspaper columns for the 
Observer UK Sunday newspaper as Richard Geefe, in which the columnist narrated his preparations for his own upcoming suicide and the book deal that would accompany this (“Time to Go will be published by 4th Estate in December, two weeks after Richard Geefe has killed himself"). Most recently, his first feature film as director Four Lions (2010), a comedy-drama about clueless British suicide bombers, won the 2011 BAFTA award for Outstanding Debut.

His reputation still largely rests, however, on three fake news series from the 1990s. In 1991-2, Morris co-wrote and presented On The Hour, a satirical radio news program which also launched the careers of Armando Iannucci (The Thick Of It, In The Loop) and Steve Coogan (I'm Alan Partridge, The Trip). On The Hour introduced many of Morris's key concerns and strategies - a blend of pitch-perfect parody of the textual features of broadcast news with surrealist language and tropes; a mastery of subversive editing; and a focus on the authority of the presenter ("hello, peasants"). The critical and popular response to On The Hour led to the same team transferring to a BBC TV version of the same concept, renamed The Day Today, and broadcast in early 1994.

In January-March 1997, UK broadcaster Channel 4 (a commercially-funded terrestrial channel with a public-service remit) transmitted six half-hour episodes of Morris's project Brass Eye, which he wrote and produced himself, and played many of the parts within the series. As well as playing the scary anchor with his own name, Morris also appeared as many correspondents: gruff veteran Ted Maul, nerdy Austen Tasseltine, toothy Alabaster Codify, and the various debate show hosts all called David (David Jatt, David Sanction, and David Compression, among them). Brass Eye presents itself as a news magazine program, with each episode focusing on a single broad theme: animals, drugs, science, sex, crime, and decline. Brass Eye returned for a one-off special, broadcast on Channel 4 on 26 July, 2001, responding to an ongoing moral panic in the UK media about paedophilia. This episode itself ignited a moral panic in the press about broadcasting standards — "Unspeakably Sick" said the Daily Mail - contributing to what was at the time the largest number of complaints to broadcasting authorities ever generated by a single program (Lockyer \& Attwood, 2009). All seven episodes have been released on a collected DVD and since October 2009 have also 
been available on an official Channel 4 YouTube channel, at $<$ http://www.youtube.com/show/brasseye $>$, although access to this may be subject to geographical variation.

Brass Eye is a sustained exposure of the machinery of the authority of broadcast news. Each episode of Brass Eye takes conventions of TV news and current affairs programming and extends them to the point where their constructed nature becomes both apparent and absurd. It highlights the technical and textual elements that combine to make up the news - "the tricks of textuality," as Hartley has it (2009, p. 313). And it exposes the mechanisms of authoritative pronouncements in broadcast news by persuading a range of public figures, from senior politicians to writers and broadcasters, to say bizarre, absurd, and nonsensical things on television because they are on television. In submitting to Morris's authority as anchor of what they believe to be a current affairs program, these figures undermine their own cultural or social authority by demonstrating that they are prepared to talk — often confidently and fluently — about subjects on which they know nothing, or are prepared to lend their image and voice to absurd public awareness campaigns about nonexistent and often surreal social problems or threats. These threats included the dangers of "heavy electricity" caused by "sodomized electrons", or of "Cake," described to MP David Amess as "a made-up drug", although this did not inhibit him from going on to ask a question in the UK Parliament about the government's strategy for dealing with cake .

\section{Brass Eye and the Strategies of Television News}

The hoaxing of these public figures is enabled by Brass Eye's exact understanding of the textual strategies of television news. Morris deploys the authority of the anchor and the interviewer, but undercuts this at the same time by making it visible. He exposes the strategies that broadcasters use by setting them in fresh contexts. He takes the formal textual elements of daily broadcast news and distorts them - music that lasts too long, graphics that are over-elaborate, visual aids that don't aid so much as call attention to themselves, a claim for authority based on technological prowess. This section highlights three areas in which 
Brass Eye satirizes the textual strategies of TV news - mode of address, visuals and graphics, and music.

\section{Mode of Address}

"Should we revive our ailing culture?" asks Morris as anchor in the "Decline" episode, staring directly into the camera. "Or should we just put it out of its misery? Or should we bring it back to life and then shoot it for letting us down so badly? You haven't got a clue, have you? But you will do, if you watch for 30 minutes." We are all accustomed to experiencing broadcast media messages as though speaking to us directly. Although addressed to nobody in particular, TV news messages address us as someone:

I find, when I turn on the news, that I am spoken to while knowing that millions of others are watching at exactly the same time and seeing and hearing exactly the same things. In each case the experience is the same. In each case it is "for me." ... The news is, in each case, appropriated by me as an aspect of my experience and yet at the same time this experience is shared by countless others. (Scannell, 2000, p. 11)

This is a key feature of the characteristic mode of address of television news. The newsreader or anchor addresses multiple, dispersed listeners as though directly, but is in fact addressing no one in particular. They look straight into the camera, outwards towards an implied other "you." It is this combination of a way of talking and a way of looking, argues Scannell, that helps to create "a public, shared and sociable world-in-common between human beings" (2000, p. 12), or what Benedict Anderson calls an "imagined community" (1991). Peters describes how such strategies were devised by early broadcasters to compensate for the perceived lack of real human content — direct address, conversational tone, a cultivated sense of intimate connection:

Media culture is a lush jungle of fictional worlds where "everyone knows your name," celebrities and politicians address audiences by first names, and conversational formats proliferate. The conventional concept of "mass communication" captures only the abstract potential for alienation in large-scale message systems, not the multiple tactics of interpersonal appeal that have evolved to counter it (Peters, 1999, p. 217).

The mode of address of TV news, then, is a stylized construction, yet one which has become taken for granted. Brass Eye highlights this again and again, addressing the viewer with 
derision and sarcastic contempt. Morris leads into the commercial break in the "Animals" episode with the words: "Find out exactly what to think — next." Towards the end of the "Decline" episode, Morris as anchor sums up the evening's talkback calls from viewers: "Your phone calls tonight have been described variously as rabid, pig-ignorant, and stultifyingly ill-informed. Thanks for those."

\section{Visuals and graphics}

Biographer Lucian Randall describes how Morris and Iannucci prepared for The Day Today by taking a short BBC news-editing training course. They were given two hours to prepare a two-minute item on the war in Bosnia using available footage, and were given four main pieces of information to include. But they found that one of their key points had to be left out as there were no matching visuals (Randall, 2010, p. 87). This understanding of the relationship between news stories and their visual content underpins many of Brass Eye's most distinctive satirical moments. In the "Crime" episode, Morris points at a monitor and says "the situation is clearly grave enough to merit a black-and-white freeze-frame." Such over-literal visuals are a key device in Brass Eye: a real elephant with the words "Mike Fox" painted on its side is used to segue into an item about a character of that name. In the "Crime" episode, Morris as reporter Ted Maul introduces a feature about the town of Cowsick: "Is alarm justified? Is time running out for Cowsick? Or is this the start of a new day - the first day of spring?" The italicised words are emphasised by Morris in turn holding up an alarm clock, by sand running out of the clock, by the scene cutting instantly from night to day, and by Morris turning the clock around to point at a spring in its workings.

As well as these over-literal visuals, Brass Eye makes extensive use of the digital graphics now central to TV news. As Crisell (2006) describes these: "Moving diagrams and distinctive script may appear on the screen: the color tones of the images may be altered and the images themselves twisted, stretched, rotated, shattered and peeled away like the pages of a book" (p. 57). Brass Eye takes these further than the actual news has time to do, exposing the ways in which graphics are simultaneously used to impose visual order on the chaos of events and to augment the authority of the broadcaster through their display of technological 
resource. The Brass Eye title sequence and links between segments, for example, feature a vertiginous CGI landscape of precipices and scrolling horizons. The graphics team, who won a BAFTA for their work on The Day Today in visualising such items as the financial news "currency cat," was the same team that worked on ITN news (Randall, 2010). The key difference was that they had months to achieve their effects for Morris's fake news, rather than the daily deadlines of TV news, so were able to create some hyperreal graphics and visual counterpoints to the nonsensical texts, such as the complex CGI graph that accompanies the following sequence in the "Animals" episode:

MORRIS (IN VOICEOVER): If you plot "number of animals abused" against "what makes people cruel" versus "intelligence of either party," the pattern is so unreadable you might as well draw in a chain of fox heads on sticks. And if you do that, an interesting thing happens - the word "cruel" starts flashing.

\section{Music}

The music for both The Day Today and Brass Eye was composed by Jonathan Whitehead and Morris himself. They analyzed the themes of real news shows, such as the BBC's Newsnight program, composed by Oscar-nominated George Fenton, in search of the right degree of gravitas (Randall, 2010). The basic theme was then exaggerated and distorted, using unexpected time signatures and extending musical cues for longer than a real news show would, in order to accentuate the program's projected sense of gravity and portent. The music is crashing, self-important, over-extended, with the final chords in each link lingering just that little bit too long. In this way, formal elements of the program draw attention to the uses of such music that normally pass unnoticed.

In one of few discussions of the music of broadcast news, Neil Postman (1985) once argued that the very fact that TV news broadcasts had theme music implicated them within what he saw as a news discourse that was disproportionately weighted towards entertaining the viewer at the expense of informing her:

as long as the music is there as a frame for the program, the viewer is comforted to believe that there is nothing to be greatly alarmed about; that, in fact, the events that are reported have as much relation to reality as do scenes in a play (pp. 104-5). 
Stuart Allan (2010), in contrast, in analyzing the opening sequences of BBC and ITN news broadcasts on UK TV, points to the use of music as a strategy of interruption:

the opening sequence, usually composed of a 15- to 20-second segment of brightly colored computer-animated graphics, rapidly unfolds to a sharply ascending piece of theme music (the use of trumpets is typical). Its appearance announces the interruption of the flow of entertainment programming by signalling the imminent threat of potentially distressing information (p. 114).

Allan sees this strategy of interruption as one of five central elements of TV news discourse. He points also to liveness, and the ways in which the opening music and graphics create a sense of urgency and immediacy which in turn contribute to the broadcast's authority; to particular uses and constructions of time and space; to an emphasis on the construction of a particular "us" and "them" formulation of implied audience as imagined community; and to a strategy of professionalism manifest in pristine, hard surfaces throughout the mise-en-scene of the news (pp. 114-15).

The strategy of liveness here is also key to Brass Eye. Even though each episode was entirely pre-recorded, each presents the illusion of liveness (Bourdon, 2000; Marriott, 2007; Day, 2009), with its corresponding claim on our attention, its exercise of authority over the viewer. The "Crime" episode opens with Morris as anchor joining a police stakeout — a caption reads "Christopher Morris crouching with police" — before running around in the dark yelling "crime is confusing." This parody of crime-based reality programming and current affairs shows such as Crimewatch derives much of its impact from its appropriation of the illusion that they are live and hence more important.

The "Decline" episode, although pre-recorded, like all of Brass Eye, presents itself as coming live from "the nerve-center of tonight's program" as Morris strides up and down before a bank of TV monitors to show "a true picture of the state of Britain.” Introducing a cross to reporter Austen Tasseltine (also played by Morris), who is live on the scene at a garage "which is raided every 35 minutes," the anchor says "we have live surveillance cameras - one of them has a reporter stuck on the front." This is a basic Morris move: calling attention to the normalized conventions of TV presenting by the carefully-placed incongruous or inappropriate word or phrase ("stuck on the front"). 
It is Brass Eye's detailed attention to such formal elements of the textuality of TV news that enables Morris to draw public figures into the show's narrative, as discussed in the next section.

\section{Public Figures and Cultural Authority}

A key element of some of the most popular, respected, controversial, and widelydiscussed fake news programs, from The Daily Show to Brass Eye is the appearance of public figures, incorporated into the show's narrative and textual strategies. Politicians, for example, are often keen to reach the demographics most likely to be regular Jon Stewart viewers Baym (2010) notes that candidates in the 2008 US presidential election appeared on entertainment talk shows such as those hosted by Stewart and Colbert 110 times during the campaign (p. 18). They will submit to the comedic frame of an interview on the show in a process that comes with the risks of what Meyrowitz (1985) describes as "lowering the political hero to our level" (268-304

Jones (2010) argues that journalism's claim to cultural and social authority has been challenged from the late 1990s on, as non-journalist media producers (such as Chris Morris) exposed its machinery and artifices, as audiences took up the possibilities offered by new and contending channels for information and discussion, and as governments and politicians privileged punditry and demagoguery, such as that practiced through Fox News in the US, through conservative talkback radio in Australia, or through much of the tabloid press in the UK. One key strategy through which Morris has contributed to this challenging of the authority of the news is through his use of unwitting participants in his programs.

In Understanding News, Hartley (1982) distinguishes between different kinds of voice in broadcast news - the "institutional voices" of the anchor and other presenters and correspondents, and the "accessed voices" of interviewees. The primary voices are, of course, the institutional ones, who address the viewer directly. Accessed voices are presented in different ways from the institutional voices of the anchor. "They are all subordinate," Hartley argues, "to the overall structure of a story as presented by the professional broadcasters" (p. 109). A TV news interview is a complex relationship of authority, in which the institutional 
voice of the interviewer draws the accessed voice of the interviewee into the frame of the broadcast, with both sides aiming to draw further authority from the process of the interview. In a vox pop, the program draws cultural authority from its engagement with ordinary people, through demonstrating its connection to their concerns and opinions. In an adversarial interview of the type practiced by the figures Morris's Brass Eye persona often most resembles, such as BBC Newsnight anchor Jeremy Paxman, the institutional voice may seek to assert authority over the accessed voice, by exposing them to the risk of contradiction or gaffe. In an interview with an expert on some topic, the institutional voice may seek to draw authority for the broadcast itself through sharing in the authority of their expertise.

Chris Morris's fake news programs used accessed voices in three key ways: in vox pops, in interviews with celebrities and politicians, and in securing the participation of public figures in hoax public awareness campaigns. In On The Hour and The Day Today, the shows included surreal vox pops with passers-by in the street, who were asked to comment on ludicrous propositions. Brass Eye extended this dramatically by persuading dozens of public figures to participate in the program, either by taking part in spoof debate shows or interviews that the celebrity believed to be real, or by agreeing to support fictitious public awareness campaigns that they were led to believe were authentic. This section considers examples of each of these three devices in turn.

\section{Vox Pops}

In a precursor to the celebrity ambushes of Brass Eye, The Day Today included vox pop segments with ordinary people in the street called "Speak Your Brains." The physical authority of Morris's persona, his delivery and demeanor, his camera and microphone, combine to command responses to even bizarre and silly questions and statements, as in this sequence from episode one:

MORRIS: Tightening up the law. Is it required today?

MAN: I think so, yes.

MORRIS: In what areas?

MAN: Certainly we have to do something about drug peddling. 
MORRIS: If they ran into the new tightened-up law would it smack them up sharp or would it catch them gradually?

MAN: I think it needs to smack them up sharp.

MORRIS: Jerk their heads back?

MAN: Oh sure. Certainly, yeah.

MORRIS: Lets see if we can nail this down. In terms of this elastic band here [he demonstrates stretching an elastic band], would you like to see the law tightened up to this tightness: tightness number one, tightness number two, or tightness number three?

MAN: I think tightness number three.

MORRIS: Tightness number three, like this? [stretches his elastic band]

MAN: I think we've really got to hammer these guys.

MORRIS: So that tightness being an average Post Office band extended over about eight inches?

MAN: Perhaps, yeah. Yeah, I think so.

At this stage of his career, Morris was not using public figures. In a rare press interview for the Guardian in July 1994, he explained:

Part of the point is the sheer randomness of those people - from vicars to builders. You're undermining any talking head on TV, by showing them talking bollocks with apparent authority. In everything I do there are enough clues, you're challenging the situation to collapse by getting stupider and stupider. (Morris interviewed in Dugdale, 1994).

The fact that Morris does, as he says here, provide more than enough clues to these interviewees is important in the following sections, which discuss his escalation of this strategy in its use on public figures.

\section{Interviews}

For Brass Eye, the idea that any random individual would serve this end was replaced with an emphasis on authentic public figures. In the "Crime" episode, first broadcast on 26 February,1997, Morris, in the guise of Zeitguest host David Compression, interviews former Conservative cabinet minister and prominent educationalist Sir Rhodes Boyson about his views on crime and punishment:

MORRIS: Do you feel that vigilantism is actually going to help in the long run? BOYSON: I think it will arise in an area where something has gone wrong. MORRIS: I mean, in Gotham City in the United States they call up a specialist vigilante agent when they're in times of real trouble, by projecting a huge luminous emergency bat sign into the sky, and he comes rushing in and so far that has worked. Is that something that should be encouraged?

BOYSON: I'd have to see it, I... 
MORRIS: Well, it looks good.

BOYSON: It would have to be a very... individual with great magnetism.

MORRIS: I think that's what it is. It's his special sign.

BOYSON: They're one-offs, that sort of thing. And it's very nice in school-mastering when you have people who are one-offs who can actually do it in a way that nobody else can do it. But don't try and get other people doing it.

MORRIS: But when he, you know, Bruce Wayne goes, then it's all going to collapse. BOYSON: Yeah, well, it's done. It's happened throughout history.

What is striking about this exchange is not that a cabinet minister is unfamiliar with Batman, but rather Boyson's willingness to pronounce authoritative opinions on this fantastic nonsense. He hesitates briefly ("I'd have to see it") but with the slightest reassurance from Morris ("it looks good"), Boyson immediately and effortlessly incorporates the Gotham City vigilante of whom he knows nothing into first his own area of professional expertise (comparing Bruce Wayne with teachers from his own experience) and second his wider cultural authority: "It's happened throughout history." Morris's authoritative performance and his appropriation of the role as television interviewer enable him to exercise symbolic power - the power to define, to name, to endorse, to persuade (Bourdieu, 1991; Thompson, 1995) - over a senior politician, drawing Boyson into complicity with whatever he tells him. The viewer is left to wonder under what other circumstances Boyson is speaking from such a position of ignorance and to what extent other senior politicians would respond in a similar way.

\section{Campaigns}

A live exchange of this kind, on which Boyson presumably had not been briefed in advance, which might have given him the opportunity to ask around about this Bruce Wayne of Gotham City, is different from the public service announcements central to each episode of Brass Eye, in which a range of journalists and broadcasters, politicians and pop stars, actors, celebrities and presenters were persuaded to lend their image, voice, and cultural status to supporting absurd social campaigns. The kinds of deception to which these public figures who appeared in Brass Eye were subject put the program in a potentially vulnerable position. Channel 4 at that time was obliged to operate under the Programme Code of the Independent Television Commission (ITC), in turn governed by the Broadcast Act of 1990, which offered only limited provision for such deception in the case of investigative journalism, not comedy programs. Interviewers were obliged to make the nature of their program clear to the 
interviewee, as well as the ways in which the interview material was intended to be used. According to his biographer, Morris saw a public interest defense here, in that exposing the willingness of celebrities and politicians to appear on television endorsing the most preposterous campaigns and causes that he could devise, was a serious project, and that a comedy program could invoke the same rationale as could investigative journalists (Randall, 2010). A complaint to the Broadcasting Standards Commission by Labour MP Barbara Follett about her use in the 2001 paedophilia episode of Brass Eye was rejected, with the Commission finding that "the means deployed to deceive Ms Follett were justified in the context of the serious issues raised by the programme, in particular the dangers of people in the public eye speaking with apparent authority about matters they do not understand" (Broadcasting Standards Commission, 2001).

The celebrity participants were given as many clues as possible that what they were being asked to say was a hoax. For some of these campaigns, Brass Eye created elaborate fronts, with dedicated office space, phone lines, and letterhead, to foster a sense of authenticity, but these were invariably given ludicrous names and logos — the antipaedophilia campaign "Nonce Sense"; the drugs awareness coalition F.U.K.D. and B.O.M.B.D.; the animal rights campaigners A.A.A.A.A.A.A.Z. (Against Animal Anger And Autocausal Abuse Atrocities in Zoos).

In the "Animals" episode, actor Britt Ekland is persuaded to promote the work of Morris's fictitious animal rights organization, despite the manifest silliness of what she is asked to say:

EKLAND: Last year, they stopped penguins catapulting each other through the glass roof at Sydney Zoo. Last month, they stopped a pig throwing itself out of a tree onto a python in a two-way death-pact in Chester. Now they want to help Karla, an East German elephant who has got her trunk jammed up her own guts.

In the "Crime" episode, several celebrities — broadcaster Tommy Vance, cricketer Geoff Boycott, film director and columnist Michael Winner — are persuaded to read some advice to new offenders which they will be shown on arriving in prison. Broadcaster Vanessa Feltz delivers this message, which she is told will be screened to murderers when they arrive in jail: 
FELTZ: Hello, you think you don't know me, don't you? Yes, but you do because I'm the shopkeeper you shot in a mindless hold-up - you blew out my guts, remember? I'm the old lady whose head you stove in with a loose wardrobe in the middle of the night, remember? I'm the little boy whose face you stabbed off in panic when I found you robbing my house, remember? I'm Marvin Gaye, shot by my own father. Oh yes, you know me, alright. Look at my eyes, murderer. You killed me. What the hell did you do that for? Look at me - feel proud, do you? Do you even know what a feeling is? I do, but I can't have any more now, because of you. You? You get out after 25 years. But me? I'm here forever. I hate you.

The language is typical Morris, undermining the discourse with the unlikely phrase ("loose wardrobe," "stabbed off”) or jarring cultural reference ("I'm Marvin Gaye"). As Gray (2009) notes, the hoax campaigns "launch a satiric attack on the abuses of celebrity and public image, mocking the frequency with which those in the public eye will lend their voice and image to political or humanitarian causes, regardless of how little research they have conducted into the issue" (p. 148).

This question of the public figures' lack of research into the campaigns they are endorsing is crucial in the public awareness sequences of Brass Eye, as these campaigns illustrate the ways in which public figures are drawn into processes of social and cultural exclusion in the news media. Each of these campaigns mobilizes celebrity participation against a cultural threat of some kind. The news, as Hartley (1992) observes, "is organized around strategies of inclusion and exclusion from 'our' community” (p. 207). In this sense, the news media work to generate and sustain our sense of collective identity, through stories that represent events, values, or people as "us" or "them." The moral panic (Cohen, 2002; Critcher, 2003; Goode \& Ben-Yahuda, 1994) is where these processes of inclusion and exclusion are brought into the public sphere, as the news media become the forum for a specific debate about the nature of "us" and the nature of "them."

The 2001 Brass Eye paedophilia special contains a sequence about the dangers of new technologies which demonstrates the dynamics of moral panic. Online games are introduced as "the latest menace to require urgent warnings from expert communicators," and ITN reporter Nicholas Owen, Labour MPs Barbara Follett and Syd Rapson, and broadcasters Philippa Forrester, Kate Thornton, and Richard Blackwood all contribute to a public awareness campaign about an online children's game featuring the fictitious character Pantu 
the dog. Broadcaster Kate Thornton explains that it's a HOECS game (pronounced "hoax"), standing for Hidden Online Entrapment Control System. Some extracts from what follows:

OWEN: Singapore police have sent us these pictures. This man has plugged his groin into his computer to get sexual pleasure from the actions of a child playing with Pantu.

THORNTON: We even have footage which would be too alarming to show you of a little boy being interfered with by a penis-shaped sound wave generated by an online paedophile.

RAPSON: We believe that paedophiles are using an area of the Internet the size of Ireland, and through this they can control keyboards.

BLACKWOOD: Online paedophiles can actually make your keyboard release toxic vapours that make you suggestible (he sniffs the keyboard). You know, I must say I actually feel more suggestible and that was just from one sniff.

THORNTON: HOECS games can cause serious damage. One child was trapped online for a whole night and, according to a psychiatric report, came away with the jaded, listless sexual appetite of a 60-year-old colonel.

BLACKWOOD: Now, here are the warning signs to show that your child might be in trouble. Are they upset? Do they smell odd? Weird question, but HOECS games actually make your child smell like hammers.

THORNTON: So come on, experts. Why is no one telling us about this stuff? There's a kid in Canada who's gone almost completely 2D and no one's doing anything about it.

FORRESTER: Please - sit your kids down tonight and tell them about HOECS games. Let's strangle Pantu.

OWEN: Let's put a bomb under Pantu's chin and stamp on his throat. Let's rip this dog's brains out.

Again, the absurdist language ("the jaded, listless sexual appetite of a 60-year-old colonel," "gone almost completely 2D," "smell like hammers") goes apparently unremarked by the participants, as do the nonsensical claims about the nature of the technology ("penisshaped sound wave," "an area of the Internet the size of Ireland"). And yet, as the introduction to the segment notes, these are "expert communicators," two of whom as members of parliament would be required to make laws on such issues, one of whom was a presenter of the BBC's leading science program Tomorrow's World, and another of whom, a senior ITN journalist, was happy to add the words "let's rip this dog's brains out" to a public awareness campaign. Moreover, as Gray (2009) has pointed out, the social threats identified in each of Brass Eye's moral panic campaigns involve foreign elements — the dangerous Czech drug "Cake", the Sri Lankan government's complicity in "heavy electricity", the Libyan festivals in which cows are shot out of cannons, and in this example HOECS 
paedophile activity in Singapore - which adds an extra dimension of Otherness to the moral panics that Morris conjures throughout the series.

As Jones (2010) points out, political discussion on television has tended to assume informed, authoritative speaking positions: "The assumption by television producers has been that 'expertise' should be the defining characteristic of who gets to speak [...] The assumption is built on the belief that such speech is designed primarily to inform or educate, not fulfil other functions of political communication" (p. 43). The accessed voices in Brass Eye work above all to expose the dubious foundations of expertise upon which such normative assumptions may be built. Moreover, Brass Eye appeared at a time when the assumptions of the network era were being challenged by the rise of new technologies of media production, delivery, and reception; by the corresponding fragmentation of audiences; and by a shifting context of popular culture in which contending claims on authority, identity, and attention now competed with those of the formerly accredited experts.

\section{Conclusion}

The surreal and aggressive nature of Brass Eye sets Morris apart from a figure like Jon Stewart, who is able to function as a trusted voice on the issues within the news, representative of what Baym (2010) describes as "an emergent paradigm of hybrid media that blends news and entertainment in unprecedented ways" (p. 5). Brass Eye is satirical fake news, but it does not blend news and entertainment. Instead, the achievement of Morris's work is to expose the textual and cultural machinery of news and current affairs. Morris does not fill a role as a trusted journalistic voice or as someone who can actually take on the mantle of Fourth Estate, as Stewart can in his often very serious and probing interviews with real public figures. As Jones (2010) argues, Jon Stewart's The Daily Show is fake “only in that it refuses to make claims to authority and authenticity, as opposed to those claims repeatedly asserted through the techniques and conventions used by news media" (p. 18). Brass Eye, in contrast, is fake news that does make those very claims to authority and authenticity, through the force of its satire staking out an alternative position from which to 
critique authority. Morris appropriates and exaggerates the textual conventions of news and current affairs, and deploys these to expose the limitations of the genre's accessed voices.

As Baym (2010) argues (p. 106), The Daily Show draws a paradoxical power and authority by claiming to be fake, which allows it to go to places that other news shows can't go; Brass Eye, in contrast, claims to be real, and draws public figures into its surreal artifice through the careful maintenance of this pretense. Where The Daily Show, in Baym's analysis, operates through a "discourse of inquiry" (p. 111), attempting to penetrate an obfuscatory political culture, Brass Eye operates instead through a discourse of exposure, revealing the strategies of broadcast news and current affairs, and the mutual complicity of broadcasters and the public figures whose voices they access.

Why does this matter? News, as a textual system, as a set of cultural practices, as a social forum and as an industrial product, operates through claims to the real built upon claims to authority. It accesses and authorizes the voices that define and delimit the contours of public debate, and it draws these voices into its own strategies of symbolic power. The achievement of Brass Eye is to bring these taken-for-granted processes and strategies to the forefront of its viewers' attention. 


\section{References}

Allan, S. (2010). News Culture, (3rd edition). Maidenhead: Open University Press.

Anderson, B. (1991). Imagined Communities, (revised edition). London: Verso.

Baym, G. (2010). From Cronkite to Colbert: The Evolution of Broadcast News. Boulder, CO: Paradigm.

Boler, M. with Turpin, S. (2008). "The Daily Show and Crossfire: Satire and Sincerity as Truth to Power”. In M. Boler (ed.) Digital Media and Democracy: Tactics in Hard Times (pp. 383-403). Cambridge, MA: MIT Press.

Bourdieu, P. (1991). Language and Symbolic Power. Cambridge: Polity.

Bourdon, J. (2000). “Live Television Is Still Alive: On Television As An Unfulfilled

Promise", Media, Culture and Society, 22 (5), 531-56.

Broadcasting Standards Commission (2001) 'Adjudication: Complaint about unjust or unfair treatment by Ms Barbara Follett MP, submitted on 11 September 2001, about Brass Eye Special, broadcast on Channel 4 on 26 July 2001", Broadcasting Standards Commission [now replaced by Ofcom], archived at

$<$ http://www.ofcom.org.uk/static/archive/bsc/pdfs/fairadj/follett.htm>, accessed 23

September 2011.

Cohen, S. (2002) [1972]. Folk Devils and Moral Panics (3rd edition). London: Routledge.

Crisell, A. (2006). A Study of Modern Television: Thinking Inside the Box. Basingstoke: Palgrave Macmillan.

Critcher, C. (2003). Moral Panics and the Media. Buckingham: Open University Press.

Day, A. (2009). "And Now... the News? Mimesis and the Real in The Daily Show". In J.

Gray, J. P. Jones and E. Thompson (eds) Satire TV: Politics and Comedy in the Post-Network Era (pp. 85-103). New York: New York University Press.

Druick, Z. (2009). "TV News Parody as a Critique of Genre”, Television \& New Media, 10 (3), 294-308.

Dugdale, J. (1994). “Taped Up For Auntie”, Guardian, 25 July, p. 16.

Ericson, R. V., Baranek, P. M. and Chan, J. B. L. (1989). Negotiating Control: A Study of News Sources. Milton Keynes: Open University Press.

Goode, E. and Ben-Yehuda, N. (1994). Moral Panics: the Social Construction of Deviance. Oxford: Blackwell. 
Gray, J. (2009). "Throwing Out the Welcome Mat: Public Figures as Guests and Victims in TV Satire”. In J. Gray, J. P. Jones and E. Thompson (eds) Satire TV: Politics and Comedy in the Post-Network Era (pp. 147-66). New York: New York University Press.

Gray, J., Jones, J. P. and Thompson, E. (eds). (2009). Satire TV: Politics and Comedy in the Post-Network Era. New York: New York University Press.

Hartley, J. (1982). Understanding News. London: Methuen.

Hartley, J. (1992). The Politics of Pictures. London: Routledge.

Hartley, J. (2009). “Journalism and Popular Culture”. In K. Wahl-Jorgensen and T. Hanitzsch (eds) The Handbook of Journalism Studies (pp. 310-24). London: Routledge.

Jones, J. P. (2010). Entertaining Politics: Satiric Television and Political Engagement (2nd edition). Lanham, MD: Rowman \& Littlefield.

Kilborn, R. (2003). Staging the Real: Factual TV Programming in the age of Big Brother. Manchester: Manchester University Press.

Lockyer, S. and Attwood F. (2009). “"'The Sickest Television Show Ever:” Paedogeddon and the British Press", Popular Communication, 7 (1), 49-60.

Lotz, A. D. (2007). The Television Will Be Revolutionized. New York: New York University Press.

Marriott, S. (2007). Live Television: Time, Space and the Broadcast Event. London: Sage. Meikle, G. and Redden, G. (eds) (2011). News Online: Transformations and Continuities. Basingstoke: Palgrave Macmillan.

Meyrowitz, J. (1985). No Sense of Place, New York: Oxford University Press.

Peters, J. D. (1999). Speaking Into The Air: A History of the Idea of Communication. Chicago: University of Chicago Press.

Postman, N. (1985). Amusing Ourselves to Death. London: Methuen.

Randall, L. (2010). Disgusting Bliss: The Brass Eye of Chris Morris, London: Simon \& Schuster.

Roscoe, J. and Hight, C. (2001). Faking It: Mock-Documentary and the Subversion of Factuality. Manchester: Manchester University Press. 
Scannell, P. (2000). "For-Anyone-As-Someone Structures", Media, Culture \& Society, 22 (1), 5-24.

Thompson, J. B. (1995). The Media and Modernity. Cambridge: Polity.

Zelizer, B. and Allan, S. (2010). Keywords in News \& Journalism Studies. Maidenhead: Open University Press. 